\title{
An Interactive Web-Based Software for Epidemiological Research Designs
}

\author{
Fatma Hilal Yagin $^{1(\mathbb{D})}$, Burak Yagin $^{1(\mathbb{D})}$, Cemil Colak $^{1(\mathbb{D})}$
}

${ }^{1}$ Inonu University, Faculty of Medicine, Department of Biostatistics and Medical Informatics, Malatya, Turkey.

Copyright@ Author(s) - Available online at https://dergipark.org.tr/en/pub/mbsjohs

Content of this journal is licensed under a Creative Commons Attribution-NonCommercial 4.0 International

License,

Received: 19March 2020, Accepted: 12 April 2021, Published online: 30 April 2021

(C) Ordu University Institute of Health Sciences, Turkey, 2021

\begin{abstract}
Objective: The aim of this study is the development of Epidemiological Research Design software that enables to determine the correct epidemiological research design have web-based, free and Turkish / English language options.

Methods: From Epidemiological Research Designs in the software developed; a definitive system has been established for Case Presentation, Case Series, Correlational (Ecological), Cross-Sectional Research, Case / Control, Cohort, Field Intervention, Clinical Intervention, Ethnography, Phenomenology, Grounded Theory and Qualitative Case Studies. For this purpose, questions are asked to the researcher to determine which research design to use. This software has been developed using the Python programming language. For this purpose, the dash library in Python was used.

Results: Determining the research design before starting a study is a very important step. Although there are some differences in the grouping of epidemiological studies in various sources, the characteristics of the methods are basically the same. It is thought that the software developed in this study will allow researchers to determine the correct research design by eliminating these differences. The developed software can be accessed at http://biostatapps.inonu.edu.tr/EATY/.

Conclusion: It is thought that the web-based software developed, free and with Turkish / English language options, will guide and contribute to researchers in determining epidemiological research designs.

Key words: Epidemiological Research Designs, Observational Studies, Experimental Studies, Qualitative Research, Python
\end{abstract}

Suggested Citation: Yagin FH, Yagin B, Colak C. An interactive web-based software for epidemiological research designs Mid Blac Sea Journal of Health Sci, 2021; 7(1):122-131

\section{Address for correspondence/reprints:}

Fatma Hilal Yagin

Telephone number: +905557545334

E-mail: hilal.yagin@inonu.edu.tr

\section{Introduction}

In order to contribute to science, researches carried out by collecting, interpreting and evaluating data in a planned and systematic manner are called scientific research. The results obtained from a small group of scientific researches are transferred to the society and new information is created about the reliability of diagnosis, treatment and applications. For this reason, the researcher must determine the scientific study subject, plan it and determine its methodology before starting the research (1). 
The purpose of Epidemiology is to investigate the distribution, frequency and causes of health problems or events in human populations, and these purposes are planned and achieved with various types of epidemiological research. Epidemiology is one of the basic disciplines of public health. Measuring disease or health problems is important in epidemiology. Data belonging to societies are collected in certain criteria and presented in graphics and tables. The health problem is presented with some criteria such as disease criteria (incidence, prevalence), death criteria (mortality rates), risks, rates, percentages, and comparisons are made with statistical methods $(2,3)$.

In health sciences, epidemiology is mainly; It is used to determine the causes of diseases and health problems, to reveal the natural development of diseases, to determine the health levels of societies, to examine and compare with other societies, to evaluate clinical research results, to evaluate the effectiveness of health services and to determine the risks of people facing certain health problems It is important to investigate the distribution and determinants of health-related conditions or events within specific populations and to use the results of these studies to control health problems. They differ in terms of research design, methods/analyzes used and interpretation because they are conducted on communities. In this sense, they differ from basic medical research conducted at the individual or even cellular level in order to explain the mechanisms of health-related events. Therefore, determining the research design is a very important step before starting a research (2-4).

The aim of this study is to develop web-based and free epidemiological research design software that can automatically determine the epidemiological research design by asking specific questions to the user. The software includes English and Turkish language options. The developed software can be accessed at http://biostatapps.inonu.edu.tr/EATY/.

\section{Methods}

\section{Hypothetical examples}

Calculations for determining epidemiological research designs in medicine and other health fields were made with the web-based software proposed in this study.

In the study has determinant calculations for observational and experimental studies from epidemiological research designs. Observational studies are examined under two headings as descriptive and analytical. Experimental studies are divided into two as clinical and field intervention studies. The epidemiological research designs found in the developed software are described below.

\section{Quantitative Research}

\section{Observational Studies}

The event examined in Observational Epidemiological studies, which is one of the epidemiological research types, is observed in its natural course and no intervention is made by the investigator to the course of the event. In other words, factors (such as age or gender) and events (such as any factor or treatment method) examined by the researcher are not under the control of the researcher and cannot be changed by the researcher. Except for the examined factor or event, all variables cannot be kept constant. Randomization can be used limitedly in some cases. The cause-effect (factor-disease) relationship may not always be determined precisely and clearly. This level of clarity may differ depending on the subject and research method used (5).

\section{Descriptive Studies}

Descriptive type of research from observational epidemiological studies are studies conducted to define the occurrence and frequency of a certain health problem or disease in a society (6). Descriptive Studies are examined in three groups as Case Presentation, Case Series and Correlational (Ecological).

\section{Case Presentation Studies}

Case Presentation is a type of study in which a rare disease picture or a different clinical form of a known disease is described in detail with clinical and laboratory findings. As the name implies, there is "one case (or 1-2 cases)" in a case report study and therefore no statistical analysis is required (7).

\section{Case Series Studies}

In case series studies, interesting findings observed in the rare case (patient) group are recorded and definitions are made for the data obtained. Such a study does not aim to examine the cause-effect relationship or to discuss whether a treatment is superior or not. Such studies are guiding studies for further studies (cross-sectional, retrospective (casecontrol), prospective (cohort), etc.). It is not appropriate to make inferences about the universe in case series studies; because there is no sample that represents the universe (6). 


\section{Correlational (Ecological) Studies}

Correlational research, also called ecological research, is like the first step of epidemiological studies. These types of studies are fast, inexpensive, often obtained from data that are routinely collected for another purpose. Here, individual people are not examined, but the data of the society are used. Data about the whole society are compared and correlated with each other. These types of studies are mostly the early examinations of the diet-disease relationship. For example, the relationship between per capita meat consumption and colon cancer was compared in various countries, and it was observed that as meat consumption increased, colon cancer also increased. However, this definition does not prove that high meat consumption increases colon cancer. In societies where meat consumption is high, fiber may be consumed less or animal fat may be consumed too much $(8,9)$.

\section{Analytical Studies}

Analytical epidemiological studies reveal whether the relationships between a health problem and various factors thought to cause this health problem are real (10). Analytical Studies are divided into three as Case-Control, Cross-Sectional and Cohort studies.

\section{Case-Control Studies}

Since the causality relationship is examined retrospectively in case-control studies, these studies are also called "retrospective" studies, which means "backwards" in Latin. First, a group of cases is taken, then a similar control group is selected, and the backgrounds and characteristics of the people in both groups are examined and compared, trying to understand and interpret similar and different characteristics (11).

For example, if a hypothesis has been created that smoking may be associated with lung cancer in the light of the results obtained from lung cancer screening, a group of patients with lung cancer is selected first in the case-control study to be planned to test this hypothesis. Then, controls with similar characteristics to those in this group are selected from among people without lung cancer. The meaning of similar features means that the relationship of the two groups is similar in terms of all features except the variable to be examined. In other words, apart from smoking habits, attention is paid to be similar in terms of gender, profession, age and similar characteristics that may be associated with the development of lung cancer. The better this method called "matching" is designed, the more meaningful the results will be. After the cases and controls are determined, all the characteristics of the people in both groups related to their health are examined. A more detailed examination is made on the variable chosen for causation. In other words, apart from asking whether or not people have been smoking, details such as how long and how much they have smoked, whether they have smoked in the past, quitting and restarting, and their presence in smoking environments, are discussed. If a good match is made in terms of other features that may play a role in the formation of lung cancer, the relationship between smoking and lung cancer can be demonstrated by making risk calculations (12).

The calculation of risk in case-control studies is called "estimated relative risk" or, more technically speaking, "odds ratio". If the estimated relative risk for lung cancer development is found to be 4 , for example, the interpretation of this is that "past or current smoking increases lung cancer risk by an estimated 4 times compared to people who have never smoked". The most important drawback of these studies is the difficulty of collecting reliable information about the past. Failure to collect reliable information about the past, sometimes due to the memory factor, sometimes due to lack of recording means that the resulting relationship will always be a controversial and "predictive" relationship. However, since these studies can be done in a short time and do not bring much cost in every sense, they are of a quality that can shed light on many causality relationships if they are well designed $(13,14)$.

\section{Cross-Sectional Studies}

Cross-sectional studies are studies conducted in the form of collecting data from a specific section of society in a specific time period. All screenings related to health or diseases are considered crosssectional in this sense. For example, by conducting a screening for lung cancer in any community, those with and without lung cancer can be identified and various characteristics related to them. During the screening, some cases that are already known to have lung cancer may be encountered, as well as new cases that are found to be sick with this screening for the first time. The prevalence of lung cancer is the prevalence obtained by dividing the old and new cases by the number of people screened. Since prevalence can be calculated in cross-sectional studies, these studies are also known as prevalence studies $(15,16)$.

\section{Cohort Studies}

In Cohort studies, a cohort group to represent the society is selected first. Cohort literally means 
"individuals with common features, a community of units". Later, this group is monitored in terms of the disease that is the subject of research. Depending on the natural course of the disease, the time required for the emergence of the disease and its death or healing, follow-up is performed for days, months, or even years. Regular and detailed data are collected about whether the monitored people encounter various risk factors that may cause the disease, and the changes in their health. During these follow-up, when there are individuals who leave the study or disappear, the initial cohort size should be well calculated, since it will not be possible to replace them. As a result, the rate of disease occurrence between individuals who have been exposed to various factors and individuals who have not encountered these factors is calculated. Cohort studies are also known as incidence studies, because the name of the disease prevalence occurring within a certain period of time is "incidence" and incidence can be calculated in these studies. The difference between the disease incidences the group that encountered the factor and the group that did not encounter the factor is called "risk attributed", and the ratio between incidences is called "relative risk" or "risk ratio" (17).

For example, in a cohort study that will be planned to examine the relationship between lung cancer and smoking habits, the cohort group should be composed of people who do not have lung cancer, that is, this must be the common feature. Later, this group is divided into subgroups in terms of smoking habit and started to be followed. Examination data regarding the development of lung cancer are collected at regular intervals from all individuals in the cohort group. In addition, smoking habits and other characteristics are recorded. This type of research continues for years, as lung cancer takes years to emerge and end. As a result, it is determined that some individuals among smokers and some individuals among non-smokers have the disease and lung cancer incidence is calculated for both groups. The causality relationship between smoking habit and lung cancer is interpreted by looking at the difference between incidences and the ratio between incidences. For example, if the incidence of cancer in smokers is $0.4 \%$; If it is found to be $0.1 \%$ for non-smokers, the relative risk is 4 , and this result is interpreted as "smokers are 4 times more likely to develop lung cancer in the future than non-smokers". Since the risks calculated in these studies are not affected by the memory factor as in case-control studies and there is no estimated risk, they are considered to be a more precise indicator of causality. The high costs in terms of time, money and manpower of these research types, which have superiority in terms of causality, are their weaknesses (18-20).

\section{Experimental Studies}

In experimental studies, factors and events (such as any factor or treatment method) examined by the researcher are under the control of the researcher and can be changed if desired. For example, a researcher can give a drug to various groups with predetermining characteristics (age, gender, etc.) in various doses and evaluate their effects. All variables other than the factor or event examined can be kept constant, or the participants or methods can be randomly divided into intervention (experimental) and control groups. This is called randomization. In addition, the cause-effect relationship can be determined completely and accurately (21).

\section{Intervention Studies}

Intervention studies are types of research that are planned in order to determine cause-effect relationships or to determine control methods. It is examined in two groups as clinical and field intervention studies (22).

\section{Clinical Intervention Studies}

Clinical trials are generally epidemiological studies planned to evaluate the effectiveness of diagnosis and treatment methods. These are mostly done to determine the efficacy and safety of various drug or treatment methods. Although it is used to refer to studies that go through the stages known as Phase I, II, III and IV, it refers to all studies conducted to test any treatment or prevention method using epidemiological methods among those who come to the clinic. Consisting of these methods, clinical epidemiology has become a sub-branch of its own scientifically. Clinical experimental studies can be designed as "parallel or synchronously controlled", "cross-controlled", "randomized controlled", "externally controlled" or, in very special cases, "uncontrolled" studies. Although there are many different design forms, the main feature of these studies is that a drug or treatment method, whose effectiveness and safety will be examined, is given to a group of patients with defined clinical characteristics and compared with a control group with the same disease who received another treatment or placebo. If the groups are selected well, the controls are matched, and the research design and data collection process are done well, it becomes possible to say to what extent the differences are dependent on the new drug or treatment method. Although various velocity, ratio and risk calculations 
are made in order to examine causality in these studies, the way of making and interpretation of these calculations is different from the calculations and interpretation of the results of observational research on communities $(23,24)$.

\section{Field Intervention Studies}

Field studies, which are among the experimental epidemiological researches, are studies planned in healthy people, unlike clinical studies. Field research is a concept that refers to experimental research on communities. The aim of these studies is to examine the efficacy and safety of any treatment or prevention method. However, unlike clinical trials, they are designed to be performed on human populations rather than on cases that come to the clinic. Communities of people can be people of a geographic area, country, settlement or any other environment. The difference is that the experimental and control groups were selected from groups, not individuals. For example, conducting various health education activities in one of two settlements with similar characteristics to control alcohol and substance addiction, and collecting and interpreting data on the change of alcohol and substance use habits in both communities over time, leaving the other on its own, is an example of a community experiment. Similarly, the chlorination and purification of the mains water of a settlement and the interpretation of the health problems here by comparing the water with another non-chlorinated settlement is a classic example of community experiment (25-27).

\section{Qualitative Research}

\section{Ethnography}

The main purpose of the ethnographic research method is to observe the participants in the cultural environment they live in and to make descriptions regarding a specific subject. What is important here is to watch the participants in their natural environment and to associate the information obtained as a result of observation with the cultural characteristics of the environment where the participants are located. The characteristics of ethnographic research can be listed as follows:

- These studies reveal to what extent the cultures they live in affect the experiences and behaviors of individuals.

- In ethnographic studies, relatively small sample sizes are studied.

- The focus in ethnographic research is the group structure and cultural environment studied. The researcher is part of the cultural environment under study and is affected by this culture.

- The basic approach followed in the data collection phase in the research is based on "unstructuredness".

- In the analysis of the data obtained, the behaviors and verbal expressions of the individuals are interpreted $(28,29)$.

\section{Phenomenology}

Phenomenology aims to examine the existence of a particular phenomenon based on the participants' perception and experience of that phenomenon. Although the development of phenomenology goes back to ancient times, it first developed as a science in the first period of the twentieth century under the leadership of Edmund Husserl (30).

In phenomenological studies, expressing and examining a subject as a phenomenon varies according to the participant's position, perspective, experiences and purpose in the formation of his perception. Therefore, every issue should not be handled as a phenomenon and not analyzed (31).

According to the phenomenological point of view, there is no single reality and the existing reality may change according to how individuals perceive the relevant phenomenon and time. The fact that different individuals perceive the same phenomenon differently in the same situation forms the basis of phenomenological research. For example, the answers given by the students taking the course to the exam questions at the end of the semester will be different from each other (32).

\section{Grounded Theory}

The most important point of any research project is that it needs conceptualization. This happens in two ways. The first is to be a preparation for the research so that the reader is informed about the focus of the study. The second is carried out by making a literature review on the subject at the beginning of the research and reveals the basic structure of the subject to be used in later studies. This method, which is expressed as an embedded theory, sub-theory or grounded theory in the literature, was created by Glaser and Strauss (1967) and was especially expanded by the studies of Strauss and Corbin (1998) and Charmaz (2002). The main purpose of this research method is to define the relationship between conceptual categories and to reveal in detail in which theoretical relationships these are formed, changed and maintained. In this research method, revealing the concept depends on the systematic collection and analysis of the data. Here, it is expected that the 
researcher will not start researching with any ideas at the beginning of the study and therefore define the real concept under the categories $(33,34)$.

\section{Qualitative Case study}

Unlike other qualitative research methods, the important point in the case study method is to focus on a specific unit of analysis, in other words, the case (case) rather than collecting and analyzing data. In case studies, the unit of analysis can be an institution, a city, a group of people, a society, a patient, a school, an application, an accident, a situation or an experience. The features of case studies can be listed as follows:

- Has a point of view that explores individual differences: Here, rather than addressing the general of the researcher, it is trying to understand a particular event with all its features.

- Considering the contextual data: The researcher handles the case together with all the subjects it covers. Therefore, certain events should be defined as the focus of the research.

- Uses the diversification method: In case studies, many data collection methods are used together in order to examine the subject in more depth.

- It has a temporary feature: The characteristics of the event examined in case studies may change over time.

- It prepares the ground for the formation of the theory: Since case studies involve making in-depth studies on a particular subject, they cover all processes and this facilitates the emergence of the theory behind the case under investigation (31).

\section{Web Based Software}

Epidemiological research design software has been developed as web-based and can be used free of charge from any device (desktop computer, laptop, mobile phone, etc.) with an internet connection. The software was developed using the DASH library in the Python programming language (35). Includes English and Turkish language options. The current software can be accessed at http://biostatapps.inonu.edu.tr/EATY/..

\section{Results}

The software consists of three main menus. First, the introduction menu (Figure 1) contains a brief description of epidemiological studies. The design determination menu (Figure 5-6-7) allows the researcher to easily determine the research design by asking a few questions for descriptive and experimental epidemiological studies. In addition, there is a table in this menu that provides more detailed information for the designated research Examples of Intervention Studies

An example for the Clinical Intervention Study:

For example, suppose a new antibiotic or cancer drug is being researched. Whether a drug used twice a day would have the same effect with less side effects should be investigated. The aim here is to determine which of the two treatment methods is more effective.

The type of research in this study is quantitative, there is an intervention (active substance is being tested) and the main aim of the study and the route followed is the effectiveness and safety of the treatment. Therefore, the related study is a clinical intervention study. When all these options are selected in the software, the criteria (Relative Effectiveness, Protectability dimension) obtained from the research appear automatically. The steps to determine the type of this study in the software are as in Figure 4.design. This table can be accessed by clicking the "Click for Detailed Information on Proposed Research Design" button that appears after the questions are answered in the design determination menu. The following examples are made to demonstrate how the software works and its principle.

\section{Examples of Descriptive Studies}

An example for the Case Series Study:

If the type of research in the relevant study is quantitative, if there is no attempt, no hypothesis and the research unit include more than one person, the relevant study is the Case Series. The steps for determining the type of this study in software are as in Figure 2.

\section{Examples of Analytical Studies}

An example for the Cohort (Follow-up) Study:

A cohort type study was conducted to examine the relationship between lung cancer and smoking. For this purpose, 2000 cigarettes selected from the society. A smoker group and a non-smoker group of 2000 people were selected and followed for a certain period of time, and as a result of this follow-up period, lung cancer prevalence was found in both groups.

The type of research in this study is quantitative, there is no intervention (there is a period of followup), there is a hypothesis (what is the risk of lung cancer in smokers compared to non-smokers), and the direction of the research is forward. Therefore, the related study is a Cohort study. When all these options are selected in the software, the criteria obtained from the research (Incidence Rate, Relative Risk, Attributable Risk, Preventability Rate, Dose- 
response relationship) automatically appear. The steps to determine the type of this study in the software are as in Figure 3.

\section{Examples of Intervention Studies}

An example for the Clinical Intervention Study:

For example, suppose a new antibiotic or cancer drug is being researched. Whether a drug used twice a day would have the same effect with less side effects should be investigated. The aim here is to determine which of the two treatment methods is more effective.

The type of research in this study is quantitative, there is an intervention (active substance is being tested) and the main aim of the study and the route followed is the effectiveness and safety of the treatment. Therefore, the related study is a clinical intervention study. When all these options are selected in the software, the criteria (Relative Effectiveness, Protectability dimension) obtained from the research appear automatically. The steps to determine the type of this study in the software are as in Figure 4.

\section{Examples of Analytical Studies}

An example for the Case Control Study:

In a study planned to determine whether there is a causal relationship between Hodgkin's disease and previous tonsillectomy; case group with Hodgkin's disease and control group intact. In this study, it is aimed to compare the probability (risk) of developing Hogkin's disease in those who have had tonsillectomy in the past compared to those who did not have tonsillectomy.

The type of research in this study is quantitative, there is no intervention (there is a backward scan), and there is a hypothesis in the research (whether there is a causal relationship between Hodgkin's disease and previous tonsillectomy), and the direction of the research is backward. Therefore, the related study is a case-control study. When all these options are selected in the software, the criteria (Odds ratio) obtained from the research appear automatically. The steps to determine the type of this study in the software are as in Figure 5.

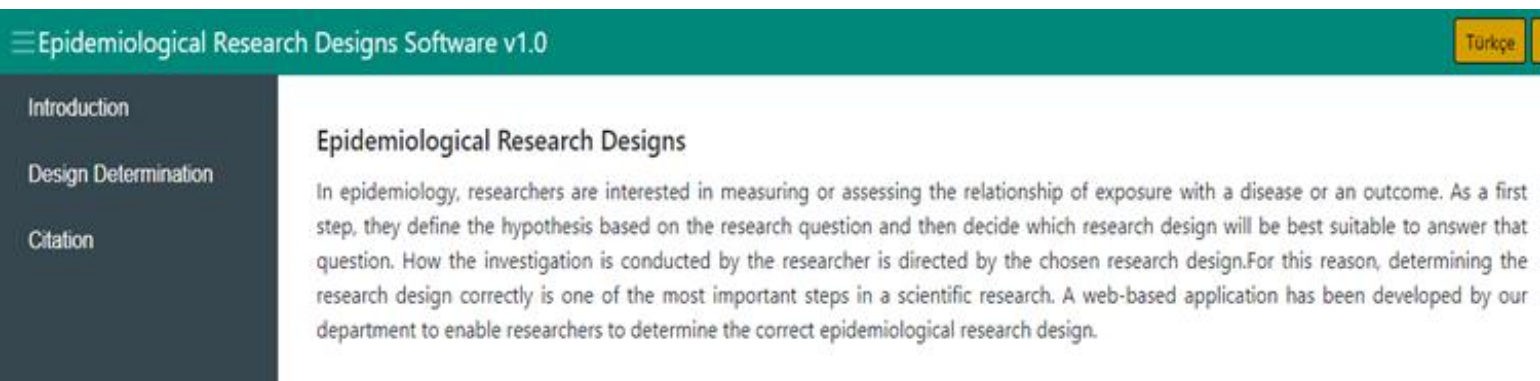

Figure 1. Introduction Menu

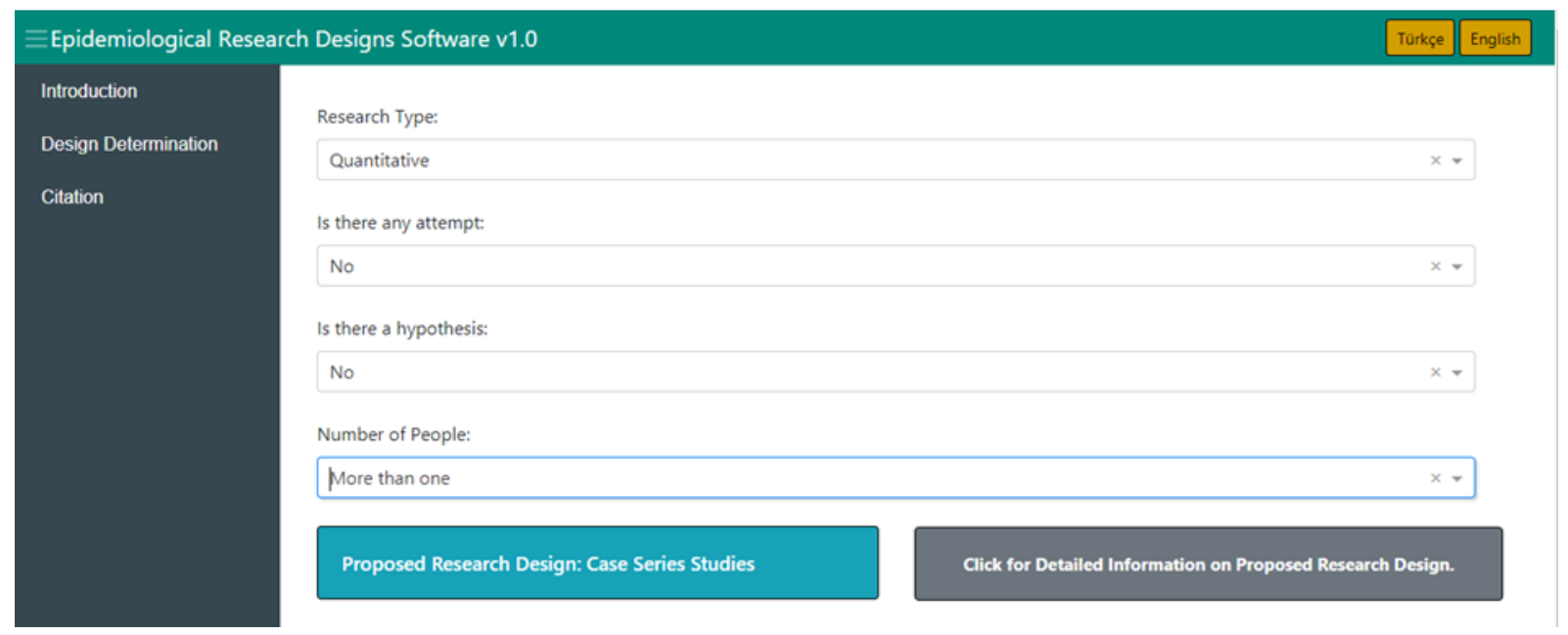

Figure 2. Results Screen in Software for Case Series Studies 


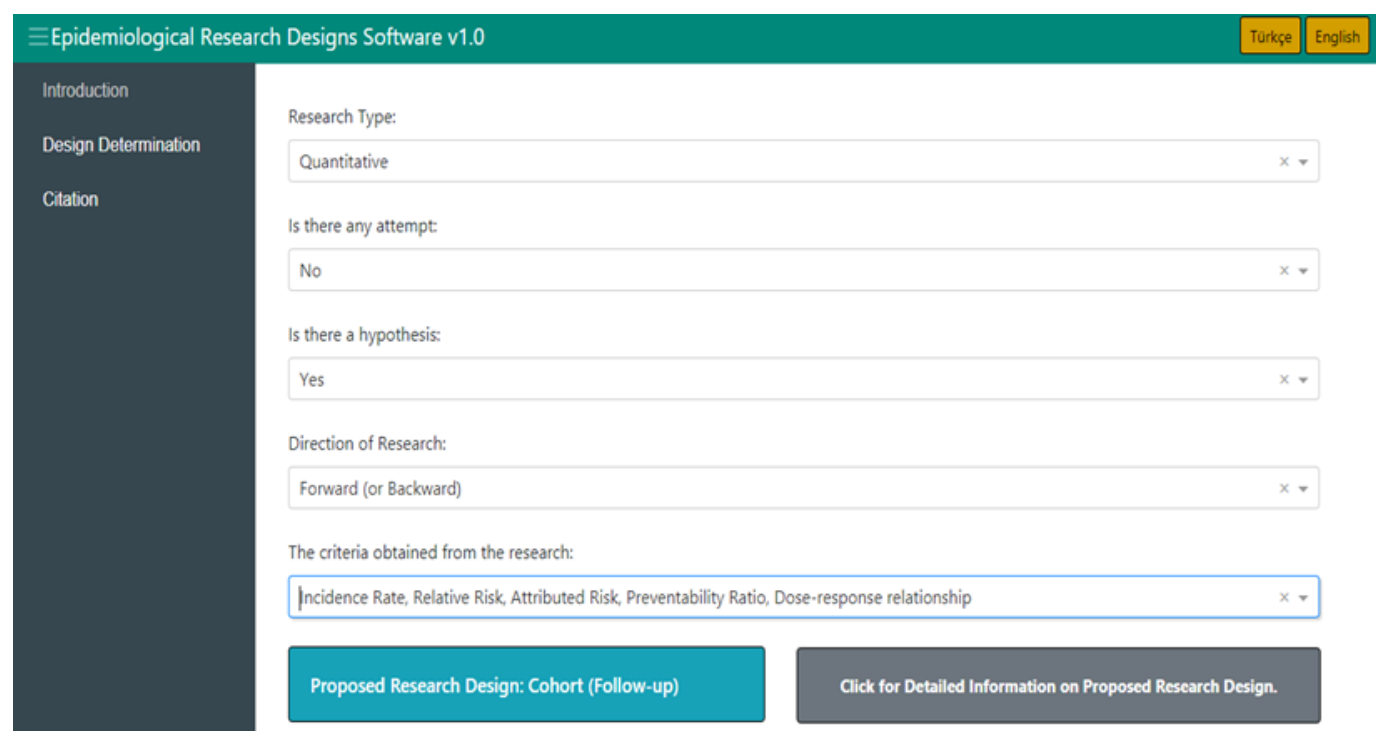

Figure 3. Results Screen in Software for Cohort (Follow-up) Studies

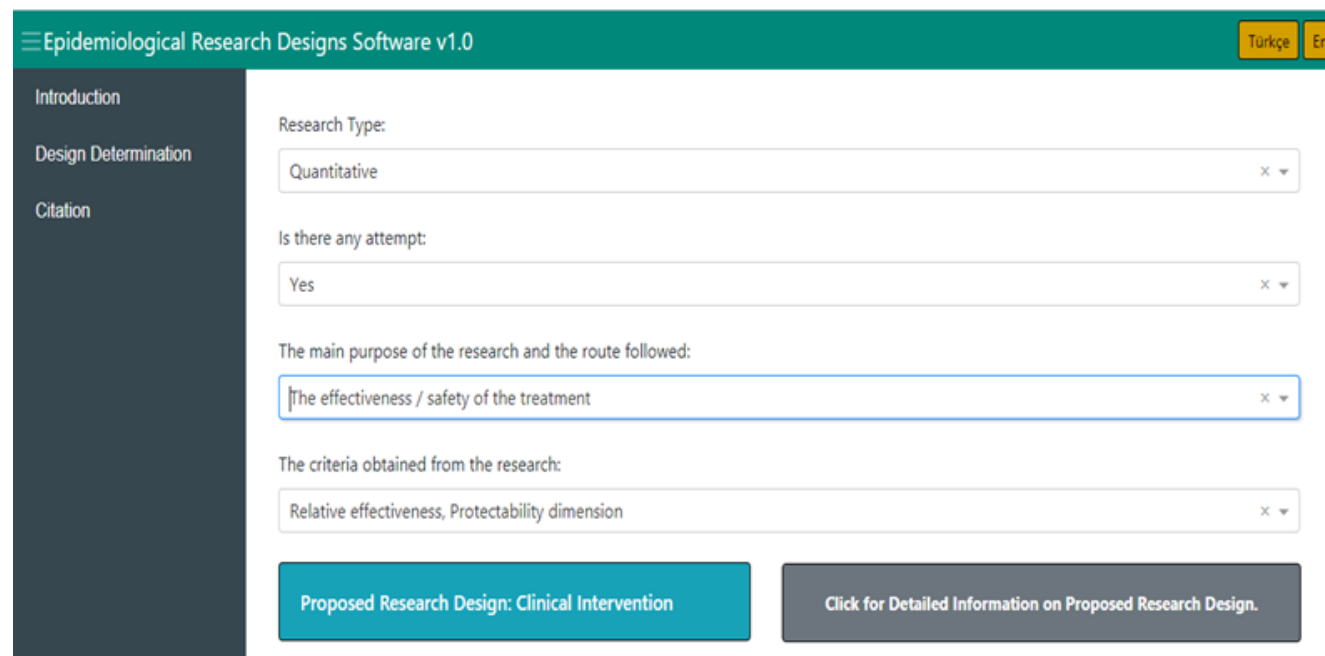

Figure 4. Results Screen in Software for Clinical Intervention Studies

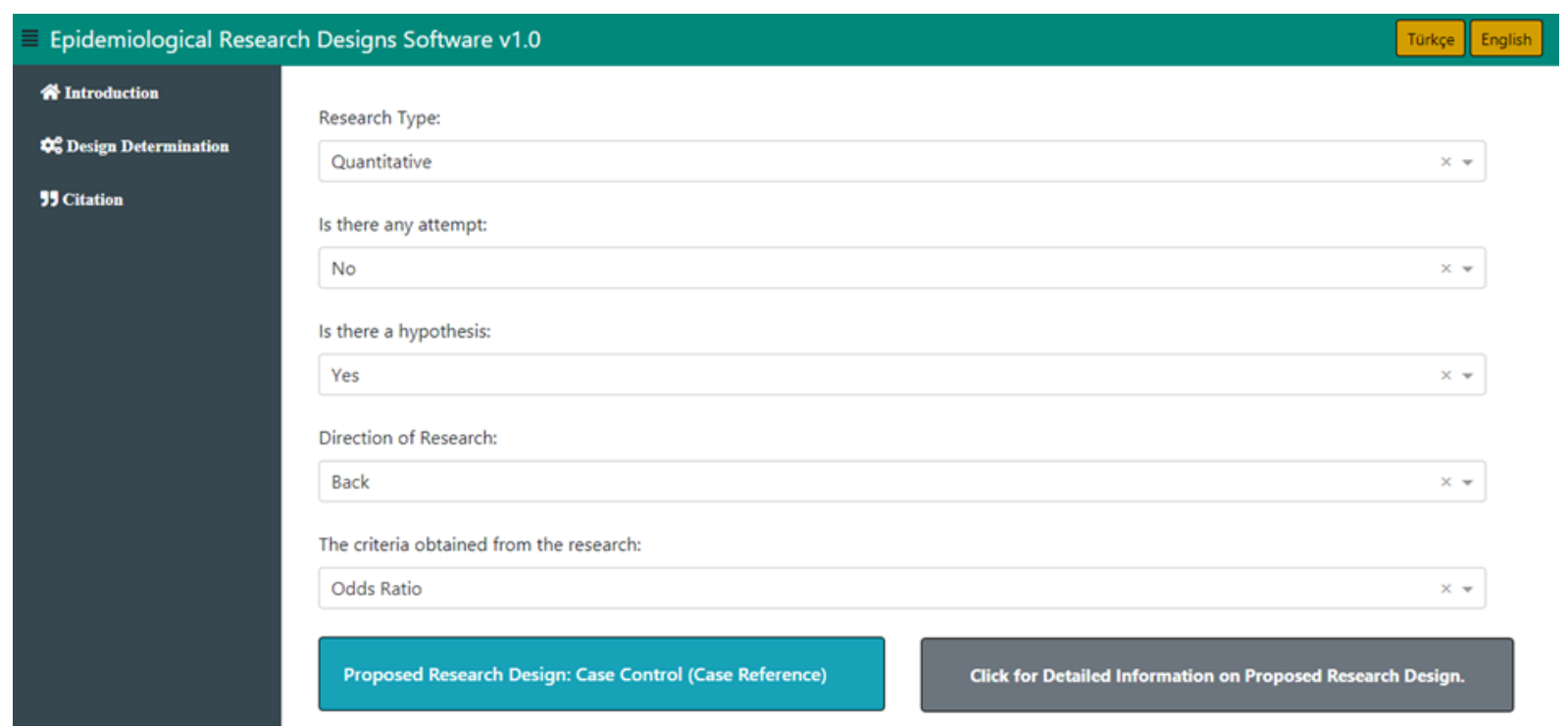

Figure 5. Results Screen in Software for Case Control Studies 


\section{Discussion}

Today, in the field of health, information is developing rapidly and physicians have to know the most accurate and reliable way to reach. It is possible to continuously and regularly research, interpret, and conduct research to improve and improve healthcare services. Proper planning of all scientific research in the field of health; an epidemiological research design is needed in order to give unbiased, reliable and realistic results and to evaluate the results correctly $(1,4)$.

In any society (this society may be a country, it can be a region, province, district of the country, employees of a factory, school students, or any social group) what the health status is, the most seen, the most killing and the most Epidemiological and biostatistical methods are used to define the quantity and quality of health problems that cause social burden. It is tried to reach some statistical findings based on the data that existed first. When this is insufficient, clearer information about diagnosis can be obtained by planning a research with epidemiological methods. For the treatment of societies whose health status has been examined and problems have been identified, health education studies are conducted at the community level to control risk sources and to change the health behaviors of individuals positively. Therefore, it may be necessary to plan and organize services to solve the problems, as well as to be successful in solving the problems by better management of the existing health system $(36,37)$.

Determining the correct research design is a very important step in epidemiological studies. Because each research design has strengths and weaknesses relative to each other. These research designs depend on the purpose of the research, its hypothesis, the number of people included in the research, the direction of the research, the criteria to be obtained from the research, etc. varies according to. There are different information in different sources in the literature for the classification of epidemiological studies. The software developed in this study can enable researchers to determine the correct epidemiological research design before starting their studies.

\section{Conclusion}

As a result, it is thought that the software will prevent information differences and misclassifications in the literature in determining the research design.
Ethics Committee Approval: Ethics committee approval is not required in this study.

Peer-review: Externally peer-reviewed.

\section{Author Contributions:}

Concept: F.H.Y, C.Ç, Design: F.H.Y, C.Ç, Literature Search: F.H.Y, C.Ç, Data Collection and Processing: F.H.Y, B.Y, C.Ç, Analysis and/or Interpretation: F.H.Y, C.Ç, Writing: F.H.Y, B.Y, C.Ç

Conflict of Interest: No conflict of interest was declared by the authors.

Financial Disclosure: The authors declared that this study hasn't received no financial support.

\section{References}

1. Ranganathan P, Aggarwal R. Study designs: Part $1-$ An overview and classification. Perspectives in clinical research. 2018;9(4):184.

2. Parab S, Bhalerao S. Study designs. International journal of Ayurveda research. 2010;1(2):128.

3. Sargeant J, Kelton D, O'Connor A. Study designs and systematic reviews of interventions: building evidence across study designs. Zoonoses and public health. 2014;61:10-7.

4. Pearce N. Classification of epidemiological study designs. International journal of epidemiology. 2012;41(2):393-7.

5. DiPietro NA. Methods in epidemiology: observational study designs. Pharmacotherapy: The Journal of Human Pharmacology and Drug Therapy. 2010;30(10):973-84.

6. Aggarwal R, Ranganathan P. Study designs: part 2-descriptive studies. Perspectives in clinical research. 2019;10(1):34.

7. Rowley J. Using case studies in research. Management research news. 2002.

8. Lu CY. Observational studies: a review of study designs, challenges and strategies to reduce confounding. International journal of clinical practice. 2009;63(5):691-7.

9. Grimes DA, Schulz KF. Descriptive studies: what they can and cannot do. The Lancet. 2002;359(9301):145-9.

10.Little RJ, Rubin DB. Causal effects in clinical and epidemiological studies via potential outcomes: concepts and analytical approaches. Annual review of public health. 2000;21(1):121-45.

11.Schulz KF, Grimes DA. Case-control studies: research in reverse. The Lancet. 2002;359(9304):431-4.

12.Lichtenstein MJ, Mulrow CD, Elwood PC. Guidelines for reading case-control studies. Journal of chronic diseases. 1987;40(9):893-903. 
13.Schlesselman JJ. Case-control studies: design, conduct, analysis: Oxford university press; 1982.

14.Rothman KJ, Greenland S, Lash TL. Case-control studies. Encyclopedia of Quantitative Risk Analysis and Assessment. 2008;1.

15.Levin KA. Study design III: Cross-sectional studies. Evidence-based dentistry. 2006;7(1):245.

16. Sedgwick P. Cross sectional studies: advantages and disadvantages. Bmj. 2014;348.

17.Levin KA. Study design IV: cohort studies. Evidence-based dentistry. 2006;7(2):51-2.

18.Grimes DA, Schulz KF. Cohort studies: marching towards outcomes. The Lancet. 2002;359(9303):341-5.

19.Euser AM, Zoccali C, Jager KJ, Dekker FW. Cohort studies: prospective versus retrospective. Nephron Clinical Practice. 2009;113(3):c214-c7.

20.Mann C. Observational research methods. Research design II: cohort, cross sectional, and case-control studies. Emergency medicine journal. 2003;20(1):54-60.

21.Miller NE. Experimental studies of conflict. 1944.

22.Abrahamse W, Steg L, Vlek C, Rothengatter T. A review of intervention studies aimed at household energy conservation. Journal of environmental psychology. 2005;25(3):273-91.

23. Forbes A. Clinical intervention research in nursing. International Journal of Nursing Studies. 2009;46(4):557-68.

24.Gluud LL. Bias in clinical intervention research. American journal of epidemiology. 2006;163(6):493-501.

25.Kristensen TS. Intervention studies in occupational epidemiology. Occupational and environmental medicine. 2005;62(3):205-10.

26. Rothman J, Thomas EJ. Intervention Research: Design and development for the human service: Psychology Press; 1994.

27.SG T. Temel epidemiyoloji. Ankara, Türkiye: Hipokrat Kitapevi. 2017.

28. Arnould EJ, Wallendorf M. Market-oriented ethnography: interpretation building and marketing strategy formulation. Journal of marketing research. 1994;31(4):484-504.

29.Denzin NK, Lincoln YS. Strategies of qualitative inquiry: Sage; 2008.

30.Jasper MA. Issues in phenomenology for researchers of nursing. Journal of advanced nursing. 1994;19(2):309-14.

31.Willig C. Introducing qualitative research in psychology: McGraw-hill education (UK); 2013.

32. Giorgi AP, Giorgi BM. The descriptive phenomenological psychological method. 2003.
33. Glaser BG, Strauss AL. The Discovery of Grounded Theory-Strategies for Qualitative Research (London, Weiderfeld and Nicolson). Přejít k původnímu zdroji. 1967.

34.Goulding C. Grounded theory, ethnography and phenomenology: A comparative analysis of three qualitative strategies for marketing research. European journal of Marketing. 2005.

35.Lutz M. Programming python: " O'Reilly Media, Inc."; 2001.

36. Wassertheil-Smoller S. Biostatistics and epidemiology: Springer; 2004.

37.Jekel JF, Katz DL, Elmore JG, Wild D. Epidemiology, biostatistics and preventive medicine: Elsevier Health Sciences; 2007. 